\title{
A EDUCAÇÃO PARA A PAZ E OS DIREITOS HUMANOS: PERSPECTIVAS TRANSDISCIPLINARES E INTEGRADORAS
}

\author{
Nei Alberto Salles Filho ${ }^{1}$ \\ Virgínia Ostroski Salles ${ }^{2}$ \\ Thais Cristina dos Santos ${ }^{3}$
}

\begin{abstract}
Resumo: A Educação para a Paz (EP) como campo de estudo e pesquisa tem suas origens ligadas aos movimentos de Cultura de Paz e Direitos Humanos, especialmente na Europa do período pós-guerra (1939-1945), relacionada à criação da Organização das Nações Unidas (1945) e a adoção da Declaração Universal dos Direitos Humanos (1948). Como campo de estudo, a EP baseia em conceitos como: violência direta e violência estrutural, desenvolvimento, democracia, cidadania, meio ambiente entre outros, demonstrando seu caráter amplo, plural e complexo, diante de um mundo de injustiças, desigualdade e exploração econômica. No contexto brasileiro e latino-americano, Paulo Freire (1985) declarou que a paz só é possível com a superação das realidades sociais perversas e com justiça social. Portanto, paz e direitos humanos são complementares, uma vez que a dignidade humana como pressuposto dos direitos humanos tem, como finalidade, o sentido de paz enquanto realização humana plena. Com estas balizas, foi construída a proposta do Núcleo de Estudos e Formação de Professores em Educação para a Paz e Convivências da Universidade Estadual de Ponta Grossa, Paraná (NEP/UEPG), que atua na formação de profissionais considerando cinco eixos: valores humanos, direitos humanos, conflitologia, ecoformação e vivências/convivências significativas. Este artigo pontua as ações do NEP/UEPG, discutindo sua proposta transdisciplinar, que aponta tanto para a construção científica quanto para práticas pedagógicas cotidianas.
\end{abstract}

Palavras-chave: Direitos. Paz. Educação.

\section{EDUCATION FOR PEACE AND HUMAN RIGHTS: TRANSDISCIPLINARY AND INTEGRATING PERSPECTIVES}

Astract: Education for Peace (EP) as a field of study and research has its origins linked to the Culture of Peace and Human Rights movements, especially in postwar Europe (1939-1945), related to the creation of the United Nations (1945) and the adoption of the Universal Declaration of Human Rights (1948). As a field of study, the EP is based on concepts such as: direct violence and structural violence, development, democracy, citizenship, environment among others, demonstrating its broad, plural and complex character, facing a world of injustice, inequality and economic exploitation. In the Brazilian and Latin American context, Paulo Freire (1985) declared that peace can only be achieved by overcoming perverse social realities and social justice. Therefore, peace and human its purpose the sense of peace as a full human

\footnotetext{
${ }^{1}$ Professor de Ciências Sociais Aplicadas (PPGCSA/UEPG). Coordenador do Núcleo de Estudos e Formação e Professores em Educação para a Paz e Convivências (NEP/UEPG) Email: nsalles@uepg.br

2 Doutoranda (Bolsista CAPES), do Programa de Pós-Graduação em Ensino de Ciência e Tecnologia (PPGECT/UTFPR), Ponta Grossa - Paraná - Brasil. Email: virginia.utfpr@gmail.com ${ }^{3}$ Mestranda (Bolsista CAPES) do Programa de Pós-Graduação em Ciências Sociais Aplicadas (PPGCSA/UEPG) - Paraná - Brasil. Email: thais.pluskota@gmail.com
} 


\section{Universidade do Extremo Sul Catarinense \\ Revista lbero-Americana de Humanidades, Ciências e \\ Educação}

UneSC Produção e democratização do conhecimento na llbero-América

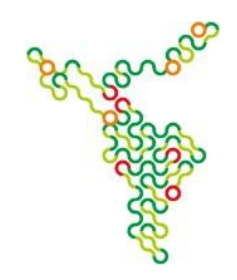

achievement. With these beacons, the proposal of the Center for Studies and Training of Teachers in Education for Peace and Coexistence of the State University of Ponta Grossa, Paraná (NEP/UEPG), was created. It works in the training of professionals considering five axes: human values, human rights, conflict, eco-formation and significant living / living together. This article points out the actions of the NEP / UEPG, discussing its transdisciplinary proposal, which points to both the scientific construction and everyday pedagogical practices.

Keywords: Rights. Peace. Education.

\section{INTRODUÇÃO}

Considera-se a Educação para a Paz como um campo de estudo em crescente construção e que possui sua história ligada ao final da década de 1950 na Europa, surgindo como forma de sistematizar conceitos e práticas pedagógicas que contribuam para a criação de uma Cultura de Paz. No Brasil, somente nos últimos dez anos, há a tentativa de sistematização das experiências e conceitos da área. Um dos espaços neste campo, no Brasil, é o trabalho do Núcleo de Estudos e Formação de Professores em Educação para a Paz e Convivências (NEP) da Universidade Estadual de Ponta Grossa, Paraná (UEPG). O NEP/UEPG, que atua desde 2008 na formação de profissionais em alternativas para a prevenção das violências e qualificação das convivências escolares foi, ao longo dos anos, organizando fundamentos para pensar a Educação para a Paz, baseado no que sustenta Jares (2002, p 131): "a paz se refere a três conceitos intimamente ligados entre si: o desenvolvimento, os direitos humanos e a democracia".

A sistematização estruturada a partir de múltiplas experiências e vivências com ações de Educação para a Paz nos últimos anos pelo NEP/UEPG, ligadas às reflexões e à busca de referencial teórico pertinente, foram indutores dos achados conceituais. Como dimensão epistemológica para a abordagem do NEP/UEPG, adota-se o paradigma da complexidade na perspectiva de Morin (2013, p. 464): "Ele não cria apenas novas alternativas e novas junções. Ele cria um novo tipo de junção que é o circuito. Ele cria um novo tipo de unidade que não é redução, mas circuito". Considerando este circuito entre as várias determinantes envolvidas na discussão sobre a paz, Salles Filho (2016) articula o campo da Educação para a Paz em cinco grandes temas integrados e 


\section{Universidade do Extremo Sul Catarinense \\ Revista lbero-Americana de Humanidades, Ciências e \\ Educação \\ Unesc Produção e democratização do conhecimento na lbero-América}

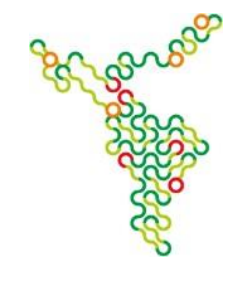

complementares (circuito), que são chamadas de "cinco pedagogias da paz".

Para entender esta construção, destaca-se a perspectiva transdisciplinar, como aquele que transcende áreas específicas de conhecimento, propondo um realinhamento paradigmático e conceitual de campos complementares. No caso do NEP/UEPG isso é fundamental, na medida em que, os profissionais que buscam capacitação, vem de campos de conhecimentos diferentes e, para entender a dimensão da Educação para a Paz, precisam reinterpretar sua formação disciplinar e integrar novas perspectivas. Assim, como o primeiro eixo, temos a Pedagogia dos Valores Humanos. Os valores humanos estão na base do comportamento humano, em todos os pensamentos e ações humanas e, criam/recriam a sociedade. Podemos dizer que os valores humanos compõem a própria história e o desenvolvimento da humanidade, sempre no fluxo que aponta valores que podem ser próximos, contraditórios ou em construção. Portanto, na busca de equilíbrio entre valores seculares e valores cotidianos, em mutação nas diferentes culturas e povos, em grupos comunitários diversos, que encontraremos as bases para a construção dos direitos humanos. Assim, de forma interligada entende-se a Pedagogia dos Direitos Humanos, não apenas como a informação e ensino da "Declaração dos Direitos Humanos Universais", mas como tudo aquilo que se apresenta como o direito à paz (RAYO, 2004) na perspectiva do que historicamente foi agregado no desenvolvimento de práticas, convenções e leis destinadas à promoção e preservação da vida na dimensão individual, social e planetária. Portanto não basta informar sobre Direitos Humanos, se não pensarmos as condições para que sejam efetivamente colocados em prática contra as injustiças e desigualdades da comunidade global.

Considerando as profundas diferenças históricas, culturais, sociais, econômicas entre tantos povos, países, grupos é natural que muitas situações presentes em relação aos Valores Humanos e Direitos Humanos sejam palco de debates edivergências. Tais perspectivas opostas, ou, os conflitos, muitas vezes levam a múltiplas formas de violência. Assim, estabelecemos o terceiro eixo, a Pedagogia da Conflitologia como espaço destinado a encontrar equilíbrio nas inúmeras diferenças humanas. Questões como resolução de conflitos, 


\section{Universidade do Extremo Sul Catarinense \\ Revista lbero-Americana de Humanidades, Ciências e \\ Educação \\ Unesc Produção e democratização do conhecimento na lbero-América}

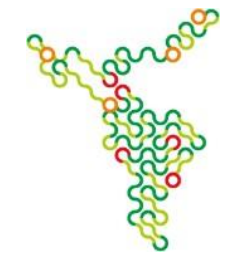

mediação, práticas restaurativas, crescem de forma muito consistente na sociedade das últimas décadas, como alternativa às "vias de fato", quando intolerância supera o respeito à diversidade. A conflitologia, também como campo de conhecimento, nessa relação integrada aos valores e direitos, gera a sensibilização ao outro ser humano e às outras culturas, abrindo novas formas de relacionamento, humanizando pensamentos, ações e reações. Valores humanos, direitos humanos e conflitologia constituem-se em pedagogias próprias, mas que, articuladas na perspectiva da complexidade promovem uma mudança de sentido do ser humano no mundo.

Ao falar de "ser humano no mundo", pensamos também em cidadania planetária, ou naquilo que Rayo (2004) nominou de "ecopacificar" a sociedade. Deste conjunto de ações do ser humano no mundo, sociedade e planeta, que também precisa ser preservado, posto que, está esgotado em seus recursos naturais, enfrentando inúmeras catástrofes ambientais nos últimos anos, é que se integra à Educação para a Paz um quarto eixo, a Pedagogia da Ecoformação, entendida como a união entre "educação ambiental junto com uma educação para ao desenvolvimento sustentável, ou a educação para os direitos humanos e a paz. Isso tudo passa pela educação para a solidariedade, do compromisso com toda a terra e com os seus habitantes" (NAVARRA, 2008, p. 251). Portanto, a ecoformação buscará e relação ser humano/ser planetário, não somente como um conjunto de práticas ecologicamente sustentáveis do meio ambiente, mas como o redimensionamento da ideia de preservar e sustentar a vida da forma mais plena e realizada no sentido da relação com todas as formas de existência no planeta. No limite, a ecoformação aprofunda na relação homem e natureza naquilo que mais existe de sensibilidade, o que poderíamos relacionar com a perspectiva da espiritualidade, não como religião, mas como transcendência. Como afirma Suanno (2014, p. 175) a ecoformação se constrói com o desenvolvimento de "uma educação ambiental, também atenta aos direitos humanos e à paz".

Portanto, as ações do NEP/UEPG - pesquisa, palestras, cursos e oficinas pedagógicas - voltadas para educadores, assistentes sociais, psicólogos, 


\section{Universidade do Extremo Sul Catarinense}

Revista Ibero-Americana de Humanidades, Ciências e

Educação

Unesc Produção e democratização do conhecimento na lbero-América

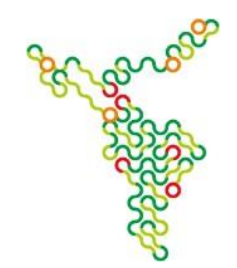

advogados, agentes de saúde e comunidade em geral, acolhem as discussões sobre a preservação da vida e do planeta, também estão sob a tensão de divergências de poder geográfico e econômico (conflitologia), envolvem legislação e busca conjunta pela diminuição dos impactos (direitos humanos), além da construção de novos valores, voltados à espiritualidade e à sustentabilidade (valores humanos). Da articulação destes quatro eixos: Pedagogia dos Valores Humanos, Pedagogia dos Direitos Humanos, Pedagogia da Conflitologia e Pedagogia da Ecoformação, acreditamos que, na perspectiva da complexidade, conseguimos intercambiar os elementos propostos pela Educação para a Paz com os saberes da educação para ao século XXI, complementados pela Pedagogia das Vivências/Convivências que incluem a corporeidade e a ludicidade como elementos pedagógicos relevantes, pois como afirma Rabbani (2003, p. 65): "A transmissão de conhecimento científico, já sabemos, não promove a paz. Apenas informar sobre a paz, as distintas formas de violência, a história da guerra e a importância do desarme ou de uma conduta eticamente correta, tampouco conleva à paz". Isso significa dizer que precisamos alterar as formas de viver e conviver, nas relações, para verdadeiramente pensarmos em um paradigma de Cultura de Paz.

\section{DESENVOLVIMENTO}

\section{Direitos Humanos: a perspectiva clássica dos setenta anos da DUDH}

Para iniciar uma reflexão sobre a Declaração Universal dos Direitos Humanos - DUDH ${ }^{1}$ precisamos dialogar sobre o termo "declaração", termo que em primazia, parece-nos algo simples, como "mais uma declaração", contudo, quando aprofundamo-nos no tema, percebemos, que como muitas leis, esta declaração, advém de muita luta e do resultado de muito sangue derramado. A partir destas questões abrimos nossa discussão, relembrando os setenta nos da DUDH. Porém novamente, o porquê de a declaração caminhar com a palavra importância? Sua explicação pode ser apontada por dois vieses. Primeiro, da própria indissocialibilidade da palavra Ser Humano. Isto é, devido à declaração surgir não como fruto de uma concessão da sociedade política ou uma dádiva real ou divina, mas sim da decorrência da natureza inerente humana do ser, uma 


\section{Universidade do Extremo Sul Catarinense \\ Revista Ibero-Americana de Humanidades, Ciências e \\ Educação \\ UneSC Produção e democratização do conhecimento na lbero-América}

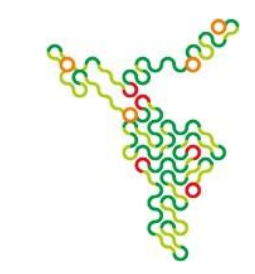

necessidade humana. Segundo, pela consequência da primeira, sendo nós, seres humanos, complexos, movido pelo desejo da evolução, da mudança, da necessidade de sermos humanos.

Mas para entendermos esta relação dos direitos como construção histórica, julga-se necessário, voltar na histórica e pensá-los sob sua fundamentação através de três tempos sintetizados: a pré-história, o mundo moderno e a contemporaneidade. Desde a pré-história, pode-se citar como exemplo das primeiras lutas pelo direito humano: 0 ato da nomeação, as cerimonias e os rituais - como o ritual do nascimento e da morte. Em relação à despedida dos mortos, pode-se destacar a obra Antígona de Sófocles representada pela primeira vez em 441 a.C. em Atenas ${ }^{3}$, uma peça teatral que conta a história de uma filha que teve seu pai e irmãos mortos durante a guerra, causada por eles mesmos, que por traição de um dos irmãos, perderam o direitos de serem enterrados, e por sua vez e terem suas almas libertas. Por consequência da negação do Rei Antígona o desobedece, questionando- o e enterrando seu ente, mesmo sem autorização, o que gerou sua morte como consequência. Esta história remete ao direito sagrado humano de chorar por seu ente querido morto. Situação, muito presente em nossa contemporaneidade, como por exemplo, a passagem das ditaduras latino- americanas para a democracia, as quais revelaram os direitos civis e políticos.

Assim como, reinvindicações de igualdade social e respeito às diferenças e principalmente as condições humanas como a "busca por mortos e desaparecidos, a defesa intransigente da recuperação da memória, a reconstituição da verdade e o reestabelecimento - mesmo tardio da justiça" (VIOLA e PIRES, 2014,p. 86).

Situação muito característica das primeiras constituições brasileiras, onde apenas quem mantivesse grande poder aquisitivo era considerado homem branco e cidadão.

Assim, o direito à rebelião, é outro fator histórico de grande importância na luta pela constituição dos direitos humanos. Isto em razão de que na idade média, diante as grandes concentrações de terras nas mãos de poucos e 0 surgimento de epidemias, aumento da fome, o direito da rebelião contra a 


\section{Universidade do Extremo Sul Catarinense}

Revista Ibero-Americana de Humanidades, Ciências e

Educação

Unesc Produção e democratização do conhecimento na lbero-América

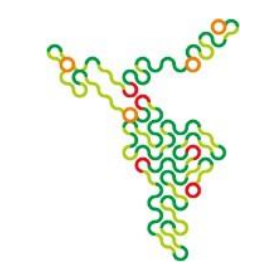

injustiça, contra a desigualdade passa a se moldar para o mundo moderno. Essa constituição se fortalece para o preceito do direito de resistência do povo contra o abuso de poder dos governantes, como um direito a revolução e não uma teoria da desobediência. Isto é "o direito de resistência dos homens, em geral, aparece quando o governo se mostra incapaz de atender ao direito de propriedade (entendida em lato sensu) do povo. Nesse caso, a rebelião torna-se necessária e coloca os indivíduos de novo em estado de natureza" (CINTRA, 2008, p. 2).

Enfim, os direitos de nomear, de decidir são construções históricas propriamente humanas, isto é, a capacidade de lutar pelos direitos de reclamar pela vida e contra a injustiça. Sendo logo, construção que se desenvolveram pela busca humana, de tornar-se humano, e, portanto, seres de direito. Por sua vez, o mundo moderno nos traz novos cenários, como o fortalecimento de muito poder e riquezas concentrado nas mãos de poucos. Segundo Bartel (2016) na França, pré-revolucionária, havia uma situação na qual $5 \%$ da população continha em suas mãos, mais de setenta por cento da renda nacional francesa, donde eram os reis que definiam as políticas.

Neste contexto percebeu-se a necessidade de lutar por seus direitos, originando três princípios importantes: da igualdade, da dignidade da fraternidade, princípios estes proclamados para a compreensão de tudo aquilo que realmente era dito como fundamental a pessoa humana. A partir destes princípios surgem as guerras de independência, constituídas na América em busca de liberdade, do rompimento com o sistema colonial e para a construção da autonomia enquanto nação, originando as primeiras declarações:Declaração da Inglaterra em 1689: elaborado pelo parlamento da Inglaterra e imposta aos soberanos: uma declaração advinda de cima, como um ato de declaração dos direitos e da liberdade dos súditos e a definição da coroa. Uma declaração restrita a aristocracia, ao clero e a um setor da burguesia comercial; Declaração universal dos direitos do homem na França em 1789: com um ideal universal pela liberdade, igualdade e fraternidade; A declaração dos direitos de cidadão de Virginia nos EUA em 1776: como resultado da luta da nação por sua liberdade.

Com esta breve revisão percebemos que a luta por direitos é algo 


\section{Universidade do Extremo Sul Catarinense \\ Revista Ibero-Americana de Humanidades, Ciências e \\ Educação \\ unesc

característico da humanidade, para a construção do ser humano, de sua existência enquanto ser. Contudo, mesmo após tantas lutas, a humanidade defronta-se a partir da Revolução Industrial e dos avanços da tecnologia e, principalmente no século XX com a chegada do que Bartel (2016) nomeia como "máquinas da morte", quando as guerras nunca mais foram iguais, e o medo tornou-se a única certeza da humanidade, principalmente após exemplos como: os Campos de Concentração no interior de uma das nações mais avançadas da Europa; Hiroshima com mais de mais de 100 mil civis mortos e Nagasaki com mais de 80 mil civis mortos no final da segunda guerra mundial, devido à explosão da bomba atômica, sem contar todas as mazelas relacionadas às violências da atualidade, não apenas relacionada às guerras, mas a pobreza, a miséria e a desigualdade social.

\section{A perspectiva dos Direitos Humanos em Johan Galtung: olhares que se alongam}

No enfoque das cinco pedagogias da paz, propostas pelo NEP/UEPG, avalia-se que perspectiva do enfoque tradicional dos Direitos Humanos limita sua relação didática com as questões da Educação para a Paz. Obviamente que são praticamente sinônimos em intenção, mas o olhar fica voltado às questões macro e distancia-se das questões micro. Além disso, pode-se dizer que a sociedade considerada moderna e que procura dar visibilidade aos direitos humanos, mesmo criticada em suas limitações atuais por um modelo que não se sustenta mais, é fruto de muitas lutas e conquistas, ainda que fugazes, mas que procuram avançar em relação às concessões a determinados grupos, via de regra, os mais vulneráveis e que mais sofrem com as violências e injustiças humanas. Este ponto é observado por Morin (2011a, p. 83), quando diz:

A democracia é uma conquista da complexidade social. Como já indicamos, ela institui, ao mesmo tempo, direitos e liberdades para os indivíduos, eleições que garantem o controle dos controladores pelos controlados, o respeito da pluralidade das ideias e opiniões, a expressão dos antagonismos e a sua regulação, impedindo que se expressem violentamente.

A democracia é, neste sentido, o requisito básico para a construção histórica dos direitos humanos. Podemos dizer, como metáfora, que os 


\section{Universidade do Extremo Sul Catarinense \\ Revista lbero-Americana de Humanidades, Ciências e \\ Educação

unesc

documentos e declarações de Direitos Humanos foram "escritos com o sangue" das injustiças perpetradas contra pessoas e grupos, até o reconhecimento como um direito assegurado social e juridicamente. Neste caminho, abordamos a Pedagogia dos Direitos Humanos com base nos estudos de Johan Galtung, quando discute que é necessário observar que o conjunto de direitos vistos pela lógica das nações, nem sempre equivale à soma dos direitos dos cidadãos na sociedade. Muitas vezes podem, inclusive, apresentar contradições. Considerando isso, Galtung (1994) diz que a história humana é fértil em produzir situações de violência extrema. Porém, é importante entender que, em determinados momentos, de acordo com os contextos onde são produzidas, as violências aniquilam os direitos humanos e, muitas vezes, não são percebidas com clareza pelos próprios envolvidos. Galtung (2006, p. 65) retrata um destes momentos:

Deixem-me começar com um exemplo dramático. Uma nação tão cumpridora da lei e orientada por regras como a alemã, com leis e regras tão profundamente incrustadas na sua cultura, tornou-se um estado nazi com 110000 de pessoas nas SS, AS e SD, exterminado onze milhões de seres humanos, dos quais seis milhões de judeus, contando o partido nazi com nada menos do que sete milhões de membros.

A esta questão, cabe o complemento que diz que na Alemanha, foram séculos de cristianismo em geral, seguido de cristianismo luterano, que poderiam ter agido como um elemento de dissuasão nessa onda de violência sem precedentes. No caso analisado, vemos que há uma questão de internalização das normas e depois sua institucionalização, onde esta consciência das normas gera um comportamento específico. Quando a consciência se torna coletiva, a institucionalização é fundamental para evitar vozes contrárias. Quer dizer, para a grande massa de alemães membros do partido nazista, e de muitos alemães, naquele momento, o discurso de Hitler, em vários sentidos foi acolhido e considerado importante para ao país. Nesse caso, mesmo com a violação dos direitos humanos e da vida humana contra milhões de judeus, a sensação é que existiria um direito maior, como nação. O controle foi mantido pelas instituições, tornando-se imaginário coletivo que, mesmo não sendo de consenso do povo alemão, era mantido também pela violência do medo, a violência simbólica. Este 


\section{Universidade do Extremo Sul Catarinense \\ Revista Ibero-Americana de Humanidades, Ciências e \\ Educação \\ UnesC Produção e democratização do conhecimento na lbero-América}

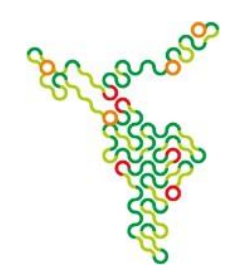

e exemplo mostra como em determinados momentos, com o argumento de preservação de direitos humanos, os próprios direitos humanos são sufocados. É a lógica de acabar com algum tipo de violência, com a própria violência. Nesse caso, nem seriam violências, mas discordâncias, conflitos entre pessoas e grupos. Tais questões em si, já são eticamente alvo de muita reflexão, de formas de acreditar no mundo e na vida. Além disso, outra reflexão é colocada por Galtung (1994, p. 84):

Duas reações típicas dos seres humanos quando sofrem privações das necessidades seriam a passividade, mesmo a apatia, e depois a atividade, mesmo revolta. A primeira pode, em última instância, levar à mobilidade e à mortalidade, talvez também ao alcoolismo, pode levar a atividades socialmente desviantes dirigidas para o exterior, tal como atos criminosos, talvez homicídios e atividade política incluindo revoluções violentas e não violentas.

Tal reflexão aponta justamente para a sustentabilidade dos direitos humanos. Nas situações onde os direitos básicos são negados, provavelmente haverá um momento de passividade e medo, seguido, ao longo do tempo de revolta contra os sistemas, que dependerão, nesse caso, manter sua ordem por meio da repressão. Porém, historicamente sabemos que tal modelo não é sustentável em longo prazo, pois, é um desequilíbrio que tende a ser modificado ao longo dos anos ou décadas, pelas próprias mudanças no mundo e nas formas de relação, como contracorrentes. Por isso, Galtung (1994) fala da dialética entre as dimensões micro e macro, referentes aos direitos humanos. As questões macro visam ao estabelecido pelos organismos internacionais, governos, legitimando espaços como a Assembleia Geral das Nações Unidas. Podemos dizer que são direitos voltados às questões amplas sobre a vida e o mundo, baseado em valores universais que pretendem alcançar uma perspectiva mundial que aponte para uma Cultura de Paz. De outro lado, muitos dos valores universais apoiados por alguns países, não tem ligação direta com direitos individuais necessários muitas vezes com urgência para as populações. Um exemplo disso é um país que oferece ajuda internacional (como alimentação, por exemplo) para outro país que passa por tragédias ambientais ou guerras, mas, muitas vezes, o país doador enfrenta, internamente, problemas com distribuição de renda na sua própria população, e, que afeta inclusive, a alimentação de seus 


\section{Universidade do Extremo Sul Catarinense \\ Revista lbero-Americana de Humanidades, Ciências e \\ Educação \\ UnesC Produção e democratização do conhecimento na lbero-América}

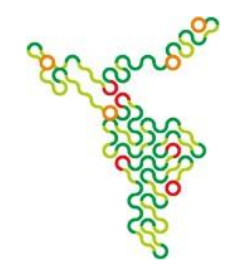

habitantes.

Como vemos, os direitos humanos, na ótica de Galtung consideram tanto as questões estruturais como humanas. Olhar o cotidiano com suas contradições e injustiças, ao mesmo tempo em que se vislumbra o global a partir dos fenômenos econômicos, sociais e culturais, faz com que a abordagem dos direitos humanos se aproxime da complexidade que a Educação para a Paz requer.

\section{Direitos Humanos no contexto da Educação para a Paz: considerações}

Conforme fomos construindo esta argumentação, acreditamos que pensar os direitos humanos na dupla dimensão - macro e micro - entre os direitos em perspectiva internacional, de aproximação de valores universais que pretendem alterar os rumos da humanidade e, os direitos individuais, que são mais diretos, como a garantia de alimentação, saúde, educação e opções dignas e inclusive, gerar mais autonomia e protagonismo como contribuição ao cenário coletivo. Tais questões são fundamentais para refletir sobre a escola no processo de produção e reprodução de estruturas sociais que impedem a concretização dos direitos humanos. Isso é analisado por Schilling (2014, p. 21) que diz: "Além das diferenças entre pessoas, o sistema meritocrático deixa de lado as diferenças entre os sexos e os grupos sociais, transformadas, pela ação da escola, em desigualdades escolares, e novamente, em desigualdades sociais, econômicas e culturais". O discurso de igualdade, sempre tão valorizado, pode apresentar desvios, como o citado (meritocracia), fazendo o caminho inverso ao que é desejado como cidadania e direitos. O mesmo se diz para a paz como direito: seria uma paz imposta pela violência, medo e silêncio, que gera uma falsa sensação de harmonia? Ou uma paz que é tecida pelos próprios problemas da humanidade, construída pela redução das situações de injustiça, desigualdade e busca da complementaridade deste binômio: valores humanos/direitos humanos.

A Pedagogia dos Direitos Humanos, no contexto da Educação para a Paz será de suma importância na explicitação de problemas mundiais e locais, de apontar as mazelas da humanidade, ou, ainda, declarar as violações aos 


\title{
Universidade do Extremo Sul Catarinense \\ Revista Ibero-Americana de Humanidades, Ciências e \\ Educação \\ UnesC Produção e democratização do conhecimento na lbero-América
}

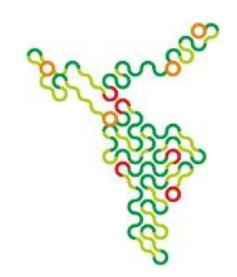

direitos humanos. Destacamos que, cada vez mais, as sociedades heterogêneas, as migrações, as mudanças climáticas fazem do cenário global complexo e difícil. Por outro lado, temos na tecnologia um vasto território a ser constituído de informação e solidariedade, fomentando redes de solidariedade planetária, onde as barreiras culturais podem ser reduzidas, favorecendo 0 intercâmbio, o conhecimento mais plural e condições de maior entendimento entre grupos e nações. E por que os direitos humanos são fundamentais neste caminho? Porque são eles que vão delimitar as ações do bem e do mal, da paz e da violência, conforme diz Morin (2011, p. 191):

O mal é o desastre, o horror da condição humana. Cada um o carrega parcialmente, mas é preciso um certo número de condições para que possa emergir. Assim, a guerra é uma das condições mais frequentes e mais radicais para a emergência do ódio e do sadismo que levam a estuprar, torturar, humilhar, massacrar.

Como observamos, os direitos humanos são uma ponte de ligação, ou mais, são as bases articuladoras de formas de percepção e comportamento. Ao mesmo tempo vão das profundezas do comportamento humanos até as discussões geopolíticas mais amplas. Ambas nos interessam ao pensar uma Pedagogia dos Direitos Humanos na Educação para a Paz. As dimensões planetárias e sociais amplas no provocam para uma cidadania global, onde os fluxos de poder político e econômico precisam ser observados com atenção, pois na outra ponta, interferem decisivamente na vida cotidiana das pessoas, em seus amores, dores, violência e paz. Jares (2008, p. 29) expressa que os direitos humanos são como um marco regulador da convivência, quando diz:

\begin{abstract}
Porque os direitos humanos significam um pacto mais sólido para uma convivência além de representar o consenso mais abrangente jamais conseguido na história da humanidade sobre os valores, direitos e deveres para viver em comunidade. Com efeito, ao indagar acerca dos pilares sobre os quais queremos construir a convivência, os direitos humanos representam opção idônea e legítima.
\end{abstract}

Por isso, a urgência da Educação para Paz como tema transversal na educação e com uma perspectiva transdisciplinar pode, nos diferentes projetos educacionais, em diferentes níveis e modalidades de ensino, levar todo este universo reflexivo e de atuação, levando às novas gerações outros modos de construir o futuro. Em meio às contradições discutidas, os direitos humanos 


\section{Universidade do Extremo Sul Catarinense \\ Revista Ibero-Americana de Humanidades, Ciências e \\ Educação \\ unesc

ganham vida nas práticas sociais e no viver/conviver diário das pessoas, muitas vezes na forma das lutas de movimentos sociais e grupos que promovem cidadania e, outras vezes, vítima da intencionalidade de grupos que manipulam informações e meios de produção, ou ainda do Estado centralizador, que administra as mazelas para seu benefício próprio. A Pedagogia dos Direitos Humanos é aquela que, de forma mais crítica, vai atuar nestas contradições, estabelecendo diálogo entre os problemas, suas origens e as possibilidades de superação.

\section{REFERÊNCIAS}

BARTEL, M. C. A problematização dos direitos humanos na contemporaneidade. In: Revista Eletrônica de Direito da Universidade Estácio do Pará. Belém, vol. $3, \quad$ n. $3, \quad 2016$ Disponível em: http://revistasfap.com/ojs3/index.php/direito/issue/view/10 Acesso em 02/04/2018.

CINTRA, R. S. Locke e o Direito de Resistência. In: Cadernos da Escola Superior da Procuradoria Geral do Estado. São Paulo, vol. 1, n. 1, p. 59-72, 2008.

GALTUNG, J. Transcender e transformar: uma introdução ao trabalho de conflitos. Tradução de Antonio Carlos da Silva Rosa. São Paulo: Palas Athena, 2006. 247 p.

Direitos Humanos: uma nova perspectiva. Lisboa, Portugal:

Instituto Jean Piaget, 1994. 252 p.

JARES, X. R. Educação para a paz: sua teoria e sua prática. 2. ed. rev. Tradução de Fátima Murad, Porto Alegre Artmed: 2002. 271 p.

MORIN, E. O método 6: ética. 4. ed. Tradução de Juremir Machado da Silva. Porto Alegre: Sulina, 2011. 224 p. 


\section{Universidade do Extremo Sul Catarinense}

Revista Ibero-Americana de Humanidades, Ciências e

Educação

Unesc Produção e democratização do conhecimento na llbero-Améríca

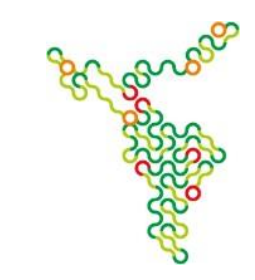

O método1: a natureza da natureza. 3. ed. Tradução de llana

Heineberg. Porto Alegre: Sulina, 2013. 479 p.

NAVARRA, J. M. Ecoformação: além da educação ambiental. In: LA TORRE, S. (org). Transdisciplinaridade e Ecoformação: um novo olhar sobre a educação. São Paulo: TRIOM, 2008. p. 235 - 260.

RABBANI, M. J. Educação para a Paz: desenvolvimento histórico, objetivos e metodologia. In: MILANI, F. (org.) Cultura de Paz: estratégias, mapas e bússolas. Salvador: INPAZ, 2003. p. 63-95.

RAYO, J. T. Educação em direitos humanos: rumo a uma perspectiva global. Tradução de Jussara Haubert Rodrigues. Porto Alegre: Artmed, 2004. 247 p.

SCHILLING, F. Educação e direitos humanos: percepções sobre a escola justa. São Paulo: Cortez, 2014. 156 p.

SUANNO, J. H. Ecoformação, transdisciplinaridade e criatividade: a escola e a formação do cidadão no século XXI. In: MORAES, M. C.; SUANNO, J. H. (orgs.) O pensar complexo na educação: sustentabilidade, transdisciplinaridade e criatividade. Rio de Janeiro: Wak, 2014. p. 205-210.

VIOLA, S. E. A., PIRES, T. V. Os difíceis ecos dos direitos humanos: participação e cultura entre as gerações. In: Revista Debates. Porto Alegre, v. 8, n. 2, p. 83$102,2014$. 
Universidade do Extremo Sul Catarinense Revista lbero-Americana de Humanidades, Ciências e Educação

UnesC Produção e democratização do conhecimento na lbero-América 